\title{
Pesquisa Psicológica Baseada em Vídeos: Sondar o Invisível a partir do Fora de Quadro
}

\author{
Danilo Sergio Ide ${ }^{1}$ \\ Instituto de Psicologia da Universidade de São Paulo, São Paulo, Brasil
}

\section{Resumo}

Nesta revisão narrativa de literatura apresentamos a síntese das descobertas resultantes de uma busca empreendida nas bases SciELO, BVS-Psi, Web of Science, PsychInfo e Psicodoc pelos termos video-methods ou visual-methods, video e camera. Após delimitar de modo geral como se organiza a filmagem na coleta de dados de pesquisa em Psicologia, detivemo-nos em particular nos trabalhos em que os próprios participantes operavam as câmeras. O interesse pela pessoa por trás da captura das imagens motivou também uma pesquisa por filmes em que a figura do cinegrafista ganha destaque. Nosso objetivo é examinar a ideia de confiar as filmagens aos participantes, em geral ligada ao debate sobre autorrepresentação, e precisar como esse expediente particular pode ser apropriado pela Psicologia. Para cumprir nossa análise fizemos uma incursão na teoria do cinema, revisando a noção espacial de fora de quadro. Observamos que na maior parte dos trabalhos, apesar do reconhecimento dado à pessoa por detrás da câmera, o fora de quadro é pouco explorado. Ele foi incorporado de fato no documentário Irène, de Alain Cavalier, filmes ficcionais de found footage como Cloverfield e pesquisas baseadas em vídeo sobre a relação homem-ambiente. Nesses trabalhos, o debate sobre autorrepresentação dá lugar a outro tipo de matéria, que interessa diretamente à Psicologia: a investigação de processos internos, imateriais como a percepção, a memória. A opção de trabalhar com os participantes fora de quadro mostra-se bastante adequada à sondagem de aspectos invisíveis do ser: esse método particular parece justo para uma pesquisa psicológica baseada em vídeos.

Palavras-chave: Metodologia, métodos visuais, vídeo, câmera, coleta de dados.

\section{Video-Based Psychological Research: Probing the Invisible from the Out-of-Frame}

\begin{abstract}
In this narrative literature review we describe the synthesis of our findings from a search undertaken on the basis SciELO, BVS-Psi, Web of Science, PsychInfo and Psicodoc for the terms video-methods or visual-methods, video and camera. After generally defining how filming is arranged in data collection in psychological research, we focused particularly on studies where participants themselves operated the cameras. The interest for the person responsible for capturing images also prompted a search for films in which the character of the cameraman stands out. Our goal is to examine the idea of entrusting the filming to participants, usually related to the discussion of self-representation, and define how this particular device may be appropriate for Psychology. To fulfill our analysis we made a foray into film
\end{abstract}

Endereço para correspondência: Av. Prof. Mello Moraes, 1721, Bloco A, Sala 115, Cidade Universitária, São Paulo, SP, Brasil 05508-030. E-mail: daniloide@usp.br

Auxílio financeiro: Coordenação de Aperfeiçoamento de Pessoal de Nível Superior (CAPES).

Trabalho apresentado na Sessão de Painéis - Metodologia de Pesquisa e Instrumentação, na 41 ${ }^{\text {a }}$ Reunião Anual da SBP, em Belém, PA, no dia 27 de outubro de 2011. 
theory, reviewing the spatial notion of out-of-frame. We noticed that in most studies, despite the acknowledgement given to the person behind the camera, the out-of-frame is underexplored. It was actually embodied in Alain Cavalier's documentary Irène, fictional found footage films like Cloverfied and video-based research on the relationship between man and environment. In these works, the discussion of self-representation is replaced by another kind of matter of direct concern to Psychology: the research of internal, immaterial processes as perception, memory. The option to work with participants out of frame is quite suitable for probing invisible aspects of being: this particular method seems to be fitted for a video-based psychological research.

Keywords: Methodology, visual methods, video, camera, data collection.

\section{Investigación Psicológica Basada en Vídeos: Sondeando lo Invisible desde el Fuera de Marco}

\section{Resumen}

En esta revisión narrativa de la literatura presentamos la síntesis de las conclusiones resultantes de una búsqueda realizada sobre la base SciELO, BVS-Psi, Web of Science, PsychInfo y Psicodoc por los descriptores video-methods o visual-methods, video y camera. Después de definir en general como la filmación se dispone en la recopilación de datos en la investigación psicológica, nos detuvimos especialmente en los estudios donde los propios participantes operaban las cámaras. El interés por la persona detrás de la captura de imágenes nos llevó también a una búsqueda de películas en las que se destaca la figura del camarógrafo. Nuestro objetivo es examinar la idea de confiar la filmación a los participantes, en general relacionada con la discusión de la auto-representación, y definir cómo este dispositivo específico puede ser apropiado para la Psicología. Para llevar a cabo nuestro análisis hemos hecho una incursión en la teoría del cine, revisando la noción espacial del fuera de marco. Hemos observado que en la mayoría de los estudios, a pesar del reconocimiento que se da a la persona detrás de la cámara, el fuera de marco es poco explorado. El se ha incrustado en realidad en el documental Irène, de Alain Cavalier, películas ficcionales de found footage, como Cloverfield, e investigaciones basadas en vídeo sobre la relación entre el hombre y el medio ambiente. En estos estudios, la discusión de la auto-representación da lugar a otro tipo de materia de interés directo para la Psicología: la investigación de los procesos internos, inmateriales, como la percepción, la memoria. La opción de trabajar con los participantes fuera de marco parece muy adecuada para sondear los aspectos invisibles del ser: este método específico parece justo para una investigación psicológica basada en vídeos.

Palabras clave: Metodología, métodos visuales, vídeo, cámara, recopilación de datos.

Antes de prosseguir o texto, uma delimitação: Por vídeo compreendemos apenas os registros feitos durante a coleta de dados de pesquisa. Portanto, não trataremos de trabalhos que eventualmente organizam esse material bruto e apresentam os resultados da pesquisa sob a forma audiovisual. É o caso de Martins (2011a, 2011b), cujo trabalho em Etnopsicologia, intitulado Encantaria na Umbanda, estrutura-se como texto, em sua dissertação de mestrado, e como vídeo, que integrou a III Festival do Filme Etnográfico do Recife. Também não trataremos de trabalhos que compõem materiais didáticos, tais como a série de oito vídeos produzidos entre os anos de 2008 e 2009 pelo LAPSI-USP (Laboratório de Psicologia Socioambiental e Intervenção da Universidade de São Paulo), voltados à educação ambiental popular.

\section{Registro em Película: Precursores na Psicologia}

Na década de 1920, Kurt Lewin já se valia de câmeras de 16 e $35 \mathrm{~mm}$ na coleta de dados 
de pesquisa. No canal TheVirtualLaboratory no YouTube temos acesso a três filmes produzidos pelo autor que tratam do desenvolvimento infantil, colocando em foco o comportamento de crianças em diferentes situações de conflito: por exemplo, em Field Forces as Impediments to a Performance (Lewin, 1925) observamos algumas crianças em suas primeiras tentativas para sentar.

No Brasil, entre os trabalhos precursores na Psicologia podemos destacar a tese de doutorado de Guidi (1972) que considerava o uso de câmeras de $16 \mathrm{~mm}$ para o registro e posterior análise do comportamento de saúvas.

\section{Registro em Vídeo: Formas Tradicionais de Filmagem na Psicologia}

Com o advento das câmeras de vídeo, tornou-se mais comum o recurso a filmagens na Psicologia. $\mathrm{O}$ vídeo é utilizado na tradição aberta por Lewin (1925). Os participantes são filmados em atividade numa situação específica. Eles podem ser considerados isoladamente, em pares (mãe e bebê, professor e aluno, paciente e profissional de saúde etc.) ou em grupos (escolares, universitários, profissionais, etc.), em contextos diversos: em casa, no berçário, na creche, na sala de aula, no recreio escolar, em consultas ambulatoriais, em reuniões etc. Os registros obtidos são então analisados em busca de padrões de comportamento, detalhes nas formas de interação social. Há também a possibilidade de os vídeos serem devolvidos aos participantes (video feedback ou videotape feedback) com finalidades terapêuticas, em terapia comportamental (por exemplo, trechos filmados das sessões são discutidos pelo paciente e terapeuta), ou didáticas, em programas de aprendizagem, de treinamento (por exemplo, o participante visualiza o próprio desempenho em situações de entrevista).

Em relação às condições de filmagem, em geral a câmera está bem à vista dos participantes, posicionada sobre um tripé ou operada por um técnico ou mesmo pelo pesquisador. Mas há casos em que ela se encontra atrás de espelho unidirecional ou camuflada sob panos. Como a intenção é registrar comportamentos observá- veis do participante, o foco da câmera deve permanecer sempre nele. Não vem ao caso deixar a filmagem a seu cargo.

\section{Outros Registros na Psicologia: Imagens Captadas pelos Próprios Participantes}

A opção de confiar ao participante o registro de imagens é mais comum em pesquisas psicológicas que trabalham com fotografias de acordo com o "método autofotográfico" (Neiva-Silva \& Koller, 2002), no qual o participante é orientado a tirar um número limitado de fotos para responder a uma questão proposta pelo pesquisador, em geral, "quem é você?".

Já o trabalho com vídeos registrados pelos próprios participantes surge aos poucos como uma opção para pesquisadores no âmbito da psicologia:

Kohatsu (2005) emprestou câmeras a três jovens que foram alunos de escolas especiais e acompanhou-os em passeios por seus bairros Durante essas excursões os participantes foram incentivados a registrar os lugares mais frequentados e apreciados, "filmar os lugares onde eles tinham recordações" (p. 109). Depois os vídeos foram vistos e discutidos com os participantes. O objetivo da pesquisa era compreender como se dava para jovens com algum tipo de deficiência a vivência fora do âmbito da escola especial, particularmente, no bairro em que moravam.

Lahlou (2011) vem desenvolvendo desde a década de 1990 um método de pesquisa com microcâmeras e microfones instalados nas laterais da armação de óculos. Participantes são instruídos a usar esse equipamento no dia-a-dia em ambientes domésticos, recreativos ou de trabalho. Como não precisam se preocupar com o manuseio da câmera, que grava automaticamente por horas, os participantes têm as mãos livres para desempenhar normalmente atividades triviais, como preparar um chá, fazer refeições, ou tarefas especializadas, como consertar computadores. Trechos dos vídeos são depois vistos e discutidos com os participantes a fim de avaliar os processos mentais envolvidos em cada uma das atividades desempenhadas. 
Mausner (2005) fez adaptações em equipamentos de trilha para que excursionistas pudessem obter registros em vídeo de suas caminhadas num parque do estado de Nova York. Por exemplo, adaptou microcâmeras na estrutura de lanternas de cabeça e afixou microfones no quadro externo de mochilas. Trechos dos vídeos também foram vistos e discutidos com os participantes. A autora estava interessada na forma com que a natureza é vivenciada através de caminhadas, buscando não apenas compreender a percepção da paisagem, mas também o modo como os participantes liam o traçado das trilhas e respondiam às dificuldades impostas por elas.

Embora ainda não seja prática recorrente em Psicologia, a opção de confiar a filmagem ao participante não é uma novidade no âmbito do cinema. Um filme que recentemente ganhou visibilidade no Brasil por adotar esse expediente foi o documentário $O$ prisioneiro da grade de ferro (Sacramento, 2003), que retratou o cotidiano do extinto presídio Carandiru combinando imagens captadas não apenas pela equipe de produção, mas também pelos próprios detentos.

\section{O Outro nos Bastidores: Autorrepresentação}

A ideia de confiar a filmagem aos participantes costuma ser remetida a um debate, travado principalmente no âmbito do cinema e da antropologia visual, sobre a autorrepresentação. Grupos que antes eram apenas o outro retratado pelas câmeras têm agora a chance de passar aos bastidores e participar mais decisivamente na produção de vídeos representativos do seu universo. Esse modo colaborativo de trabalho, que procura incluir o participante na concepção, captação e edição das imagens é prática comum hoje, por exemplo, em pesquisas que empregam o vídeo participativo (participatory video).

A tradição de confiar a filmagem aos participantes pode ser remontada à década de 1960 . No verão de 1966, Worth e Adair (1970) emprestaram câmeras de $16 \mathrm{~mm}$ a seis índios navajos (sete se considerarmos que uma das participantes ensinou sua mãe a operar a câmera), resultando em sete filmes com cerca de 20 minutos de duração e cinco filmes de 1 a 2 minutos. A experiência com os navajos teve apenas uma limitação técnica. Como não houve captação de som, todos os filmes resultantes são mudos. Mas isso não significa que experiências significativas com o som não houvessem ocorrido anteriormente.

Na Crônica de um Verão, Rouch e Morin (1961) exploraram a captação de som sincrônico para dar voz a um grupo heterogêneo de trabalhadores na França. E antes mesmo desse filme, Rouch (1958) já utilizara a banda sonora de maneira bastante original em Eu, um negro, no qual sobrepôs às imagens editadas uma locução feita por Oumarou Ganda, o protagonista do filme. Segundo Piault (1997), foi a primeira vez em que deram a palavra a um africano. O filme não continha apenas a interpretação do etnógrafo branco, mas dos próprios negros etnografados, que ofereciam uma "versão autóctone dos acontecimentos" (p. 189).

O próprio Ganda talvez discordasse dessa interpretação. Posteriormente ele se distanciou de Rouch, passando a dirigir os próprios filmes. Para marcar esse distanciamento, chegou a dizer que toda vez que fazia um filme, matava Rouch (citado por Henley, 2009, p. 331). A afirmação a princípio causa certo impacto. Mas casos de morte simbólica dos mestres não são tão isolados no cinema. Não é difícil encontrar exemplos de diretores que pretenderam expurgar as influências de seus predecessores.

O filme $5 x$ favela, agora por nós mesmos (Carneiro et al., 2010) procura já no subtítulo deixar marcada a sua diferença em relação à sua primeira versão, Cinco vezes favela (Farias, Borges, Diegues, Andrade, \& Hirszman, 1962). Anuncia-se agora um novo sujeito da oração. Se na década de 1960 "eles - cinco diretores de classe média que não pertenciam à favela - falavam pelos favelados", agora, 48 anos depois, "nós os próprios moradores da comunidade - falamos por nós mesmos". Esses enunciados se aproximam de duas formulações propostas por Nichols (2007) em sua introdução ao documentário:

\section{Eu falo deles para você (p. 40).}

Nós falamos de nós para você (p. 45).

$\mathrm{Na}$ primeira, o sujeito e o objeto remetem a distintas pessoas, pressupondo que diretor e 
grupo retratado estão em campos separados. $\mathrm{Na}$ segunda, não há distinção de pessoa: "Essa formulação desloca o cineasta da posição em que estava separado daqueles a quem representa para uma posição de unidade com estes últimos" (Nichols, 2007, p. 45).

Podemos reconhecer o mesmo tipo de reposicionamento da terceira para a primeira pessoa, tal como enunciado em $5 x$ favela, agora por nós mesmos, em projetos de outros grupos, que se consideravam igualmente "sub-representados ou mal representados" (Nichols, 2007, p. 172) pelo olhar dominante, em geral externo a eles. Foi o caso da produtora Isuma, fundada por inuítes do Canadá (entre os quais se destaca Kunuk (2001), diretor do premiado filme Atanarjuat, o corredor), descontentes com a forma com que o grupo era representado no cinema desde Nanook, $o$ esquimó (Flaherty, 1922); bem como do Grupo Medvedkin, formado por operários da Rhodia, insatisfeitos com a visão romântica dos trabalhadores apresentada por Marker e Marret (1968) no documentário Até breve, eu espero.

Essa "tendência reequilibradora e corretiva" (Nichols, 2007, p. 172) está presente também nas autoetnografias indígenas (o exemplo brasileiro mais notório é o projeto Vídeo nas Aldeias, que desenvolve a formação e produção audiovisual de tribos indígenas) e nos projetos de TVs comunitárias, caso da TV Maxambomba e da TV Pinel. A primeira, criada em 1986 pela comunidade de Rancho Fundo, na periferia de Nova Iguaçu (RJ), combatia a imagem negativa geralmente associada ao cotidiano em bairros periféricos. Já a segunda, criada em 1996 no Instituto Philippe Pinel (RJ) e ainda em atividade, busca uma contraposição aos estereótipos comumente associados aos internos de instituições psiquiátricas. O slogan adotado pela TV Pinel é justamente "por uma nova imagem da loucura" (Miranda, 2007, p. 204).

\section{Visão de Dentro e de Fora}

Embora apresente no título uma referência a Cinco vezes favela, é para outro filme que $5 x \mathrm{fa}$ vela procura dar uma resposta: "Cidade de Deus é um filme que o cara de fora [da favela] viu os traficantes e fez um filme sobre isso. . . Agora [5x favela, agora por_nós mesmos] é um filme com a nossa visão", diz Luciano Vidigal, um dos diretores do filme, em entrevista para o Portal Vermelho (2010, para. 3).

De fato, para uma geração de novos diretores brasileiros, Cidade de Deus (Meirelles \& Lund, 2002) coloca-se como o cânone a ser superado. Em entrevista ao Estado de São Paulo, Jeferson De, um dos representantes dessa geração, disse: "A relação era de admiração e ódio. Acho que, de alguma forma, está ocorrendo aqui a nossa superação do complexo de Édipo. Fernando [Meirelles] é o pai cuja influência precisamos matar, para seguir em frente" (citado por Merten, 2010, para. 4).

Aqui praticamente se repete a frase de $\mathrm{Ou}$ marou Ganda. Lá, o que justificava o distanciamento, a "morte" de Rouch, era a afirmação de uma diferença radical entre ambos, baseada em suas respectivas origens. Ganda dizia: "Ele vê com um olho francês, e eu sou nigeriano" (citado por Gonçalves, 2008, p. 160).

Se pensarmos no paradoxo da alteridade colocado por Piault (1997) - a saber, "Como mostrar e entender a diferença sem a tornar irredutível nem a reduzir ao idêntico?” (p. 190) -, a posição de Ganda e dos diretores de $5 x$ favela nos leva à irredutibilidade entre os diferentes: um francês como Rouch entenderia um nigeriano apenas de modo distorcido; um "cara de fora" como Meirelles nunca representaria corretamente o olhar dos moradores da favela. Ao adotarem essa lógica controversa, que idealiza a visão de dentro por uma suposta pureza e problematiza a visão de fora pela existência de uma mediação, chegaram à conclusão de que para reparar tais distorções era preciso que alguém originário do grupo passasse aos bastidores e assumisse a direção, o que efetivamente aconteceu nos dois casos. Apostavam que só assim a diferença poderia ser mostrada e entendida adequadamente.

Mas por mais que busquem se afastar de Cidade de Deus, os cinco curtas que compõem $5 x$ favela não parecem tão opostos ao filme de Fernando Meirelles quanto almejam seus diretores. Embora predominem personagens ligados à criminalidade em Cidade de Deus, não 
podemos esquecer a presença de um personagem boa-praça que se ajeita na vida sem cair na bandidagem. É o caso do narrador da história, Buscapé, personagem que, apesar de participar secundariamente dos acontecimentos, recebe uma boa caracterização, tendo bem delineada ao longo da narrativa a sua trajetória afetiva e profissional. A primeira descreve suas tentativas de perder a virgindade: Buscapé investirá sem sucesso em Angélica, perderá uma oportunidade com a atendente da padaria que esteve prestes a assaltar e finalmente conquistará uma jornalista. A segunda descreve seu caminho até o estágio no jornal: Buscapé trabalhará no supermercado, tentará sem sucesso entrar no crime, entregará jornais e por fim conseguirá um grande furo para o jornal com a foto de Zé Pequeno assassinado.

Como exemplo de personagem bem sucedido que supera a pressão do crime, o Buscapé de Cidade de Deus é uma espécie de duplo do personagem Maicon do curta "Fonte de renda" de $5 x$ favela. Ainda podemos pensar em outros casos em que a versão de fora em Cidade de Deus (incluindo também os produtos a ele associados, como o curta Palace II e a série televisiva Cidade dos homens) e a de dentro nos cinco curtas que integram $5 x$ favela não divergem profundamente. Podem ser facilmente consideradas como variações de um mesmo tema.

A relação entre pessoas de dentro e de fora da comunidade está presente em Cidade de Deus e no curta "Fonte de renda" de $5 x$ favela, só que há uma inversão. No primeiro, o playboy Tiago compra na zona sul roupas de marca para o traficante Benê. No segundo, Maicon compra no morro maconha para o playboy Edu.

A pipa perdida que cai em outra vizinhança é o elemento comum no episódio Cidade dos homens: os ordinários (Lund \& Tripa, 2003) e no curta "Deixa voar" de $5 x$ favela. Mas novamente há uma inversão: no primeiro a pipa cai no condomínio de ricos; no segundo, na favela rival.

Nos dois lados temos histórias centradas em duplas mirins e seus esforços para ganhar alguns trocados. Os garotos Laranjinha e Acerola, do curta Palace II (Meirelles \& Lund, 2000) aplicam sem sucesso um pequeno golpe na própria comunidade, quase assaltam um trabalhador bê- bado, mas desistem e resolvem fornecer carne para o churrasquinho de gato. Wesley e Orelha, personagens do curta "Arroz com feijão" de $5 x$ favela, conseguem faturar no asfalto, mas como são assaltados acabam aplicando um golpe no aviário da favela.

Situações causadas por problemas com serviços básicos, como correio e energia elétrica, que não funcionam igualmente na favela e no asfalto, são retratadas no episódio Cidade dos homens: correio (Lund \& Lins, 2002) e no curta "Acende a luz" de $5 x$ Favela.

O curta "Concerto para violino" de $5 x$ favela mais os longas Bróder (De, 2010) e De passagem (Elias, 2003) formam variações do tema: o reencontro dos amigos de infância que seguiram diferentes destinos; sendo os dois primeiros a visão de dentro e o terceiro, seu duplo de fora.

Por essas correspondências entre as versões de dentro e de fora, percebemos que a diferença, portanto, não é tão irredutível, o que enfraquece a ideia de que a visão de fora seja de todo descabida, como creem os diretores originários da comunidade. Chama atenção também o fato de apenas a figura do diretor ser questionada por sua origem externa ao grupo. Dificilmente encontramos o mesmo questionamento sobre a atuação de "caras de fora", como Matheus Nachtergaele em Cidade de Deus, Caio Blat em Bróder, Hugo Carvana em $5 x$ favela. Aparentemente as diferentes origens, que importavam tanto no caso dos diretores, são menos significativas no caso dos atores.

\section{Dentro e Fora do Campo Visual}

A existência de duas medidas talvez corresponda às diferentes posições do diretor e do ator em relação aos limites visuais da tela. Um está fora de nossa vista e o outro, dentro de nosso campo de visão. Embora não vejamos o diretor, nem por isso duvidamos de que ele concretamente exista, em carne e osso, com suas virtudes e vícios. Por outro lado, por mais que a presença do ator nos seja dada ao olhar, percebemo-lo mais pelo personagem que interpreta do que por sua figura empírica, ou seja, enquanto o filme durar, ele contará mais como ficção. A princípio 
parece razoável dizer que estar dentro ou fora de nosso campo visual significa pertencer ou não ao universo do filme. Mas há uma imprecisão nessa afirmação que se evidencia assim que analisamos detalhadamente as relações de espaço constituídas pelo filme.

Para se referir à porção de espaço que se descortina na tela a teoria de cinema convencionou o termo campo (em inglês, on-screen, em francês, champ). Mas o "espaço fílmico" (Aumont, Bergala, Marie, \& Vernet, 1995, p. 19), o universo onde se desenrolam os acontecimentos do filme, não se resume apenas ao campo abrangido pela vista do espectador e demarcado pelas bordas da tela. Resta ainda outra porção de espaço, a que se estende além dos limites visuais fixados pelo enquadramento. Esse espaço não imediatamente visível, não incluso no campo, mas que lhe é vizinho recebe o nome de fora de campo (em inglês, off-screen, em francês, hors-champ). $\mathrm{O}$ fato curioso é que embora pertença ao espaço fílmico o fora de campo possui a princípio uma existência apenas potencial. Ele permanecerá uma virtualidade, a menos que venha a ser concretizado por um movimento de câmera (por exemplo, um plano fixo seguido por um travelling que amplia nossa percepção do espaço fílmico) ou pela inserção na montagem de planos de uma mesma cena, porém tomados de ângulos diferentes (por exemplo, o personagem olha para algo que não aparece na tela e no plano seguinte vemos o objeto olhado por ele).

Mas o fora de campo não é o único espaço que não é visível pelo espectador. Há também o fora de quadro (em inglês, out-of-frame, em francês, hors-cadre), o "espaço da produção do filme, onde se exibe e funciona toda a aparelhagem técnica, todo o trabalho de direção" (Aumont et al., 1995, p. 29). Trata-se do espaço situado atrás da câmera ao qual não temos acesso por conta de uma simples limitação técnica, já que a câmera registra apenas a imagem do que está situado diante dela e nunca do que está atrás, salvo na situação especial de se filmar com um espelho no fundo do cenário. Assim é possível obter não apenas a imagem dos atores em cena, como também, a partir do reflexo no espelho, a imagem da equipe atrás da câmera. Essa é a única situa- ção em que essa limitação técnica é contornada. Nem mesmo o uso de mais de uma câmera seria capaz de resolvê-la. Suponhamos um filme que apresenta os bastidores de uma filmagem. Com a primeira câmera temos o registro dos atores em cena. A segunda, colocada perpendicularmente à primeira, registra os atores na frente da câmera $\mathrm{e}$ a equipe atrás nos bastidores. Na montagem podemos apresentar as imagens da primeira câmera, mostrando os atores em cena, o filme dentro do filme. E em seguida mostramos as imagens da segunda câmera para representar também a atuação da equipe nos bastidores. Mas embora fiquemos com uma imagem global do que se passou na frente e atrás da câmera podemos estender o questionamento, agora, em relação à segunda câmera: o que estava atrás dela? De nada serviria o emprego de uma terceira, uma quarta e assim por diante, pois sempre faltaria a imagem do que estava atrás da última câmera. Essa imagem praticamente impossível de ser registrada é o fora de quadro.

\section{O Fora de Quadro e o Campo}

A consideração do fora de quadro torna mais complexa a relação entre espaços visíveis e não visíveis pelo espectador. Ao contrário do fora de campo, o fora de quadro nem sempre se relaciona por contiguidade ao campo. De fato, se nos detivermos na análise do espaço fílmico, observaremos casos em que o fora de quadro e o campo pertencem a domínios distintos, completamente alheios entre si. Dependendo da relação espacial construída pelo filme, o fora de quadro se torna um espaço incompossível com os acontecimentos apresentados no campo. Tomemos um exemplo em que isso se torna patente:

Em algumas cenas de diálogo no filme Dia de outono (Ozu, 1960), há primeiro o plano de um personagem, apresentado frontalmente no campo, interpelando alguém que não aparece na tela, seguido pelo plano de outro personagem, visto também de modo frontal, respondendo ao primeiro. Considerando apenas a situação de gravação, quando o primeiro plano foi filmado, $o$ ator tinha à sua frente a equipe de filmagem. Mas quando consideramos o universo retratado 
pelo filme, o ator ou, precisamente, o seu personagem não dialoga com a equipe, mas com o outro personagem que por meio da montagem é situado no campo à sua frente. Temos então duas relações espaciais: uma que se dá durante a gravação e outra que se forma somente por meio da montagem. Se no espaço da gravação há a equipe de filmagem, no espaço fílmico construído pela montagem, a sua presença deixa de contar. E mesmo em relação à temporalidade há uma distinção, pois embora a equipe e ator fossem contemporâneos durante a gravação, a ação da primeira nos bastidores e a atuação do segundo em cena deixam de coexistir num mesmo tempo após a montagem. Fica caracterizado também um tempo da gravação e um tempo fílmico construído pela montagem.

O fora de quadro pertence justamente ao espaço e ao tempo da gravação. Mas há situações em que ele conta também na composição da relação de espaço e tempo fílmico. Tomemos agora o filme Santiago (Salles, 2007). Em algumas cenas temos o mordomo Santiago, também apresentado frontalmente no campo, contando suas histórias. Por vezes há uma interrupção e ele se dirige a alguém que não aparece no campo. Mas a imagem dessa pessoa não aparecerá num plano seguinte. Permanecemos com Santiago em campo e ouvimos apenas a voz de um dos integrantes da equipe de filmagem que lhe passa instruções. É justamente o som o elemento capaz de representar o que a imagem não mostra. Se não fosse pela voz, para deixar vestígios da presença da equipe no espaço contíguo ao campo, o fora de quadro permaneceria incógnito.

Diferente da situação anterior no filme Dia de outono, em que o fora de quadro concernia apenas ao espaço e tempo da gravação, no caso de Santiago, a equipe fora de quadro também está integrada ao espaço e tempo fílmico.

A mesma integração é visível no projeto Vídeo nas Aldeias. Como nota Bernardet (2004, p. 8), em alguns filmes se observa nitidamente a intimidade entre a câmera e as pessoas filmadas. Vemos muitas vezes elas se dirigindo justamente à câmera para comentar o que estão a fazer. Esses comentários espontâneos se devem ao fato de os índios se encontrarem completamente à vontade diante do cinegrafista, na maioria das vezes alguém pertencente à mesma aldeia. Para Corrêa (2004), uma das coordenadoras do projeto, "a proximidade que resulta desta outra forma de se posicionar permite à pessoa filmada fazer parte da construção do filme" (p. 37). Ela passa a determinar o que deseja expor à câmera e como isso será apresentado. O filme é então construído a partir de dois olhares: "o da pessoa que filma e da que consente em ser filmada" (p. 37).

Entretanto apesar da homogeneidade conferida pela identidade comum entre "filmador" e "filmado", há uma distinção clara entre os seus papéis na constituição de cada plano do filme. $\mathrm{O}$ último é todo prosa para a câmera. Já o primeiro adota certo pudor: ele mais olha através da câmera e pouco fala. De fato ele só falará quando for apresentado no campo. Na cena final do filme Das crianças ikpeng para o mundo (Txicão, Txicão, \& Txicão, 2001) vemos quatro garotos brincando em um rio. Um deles então olha em direção à câmera e diz: "A gente já acabou de se apresentar, agora é a sua vez." Há um corte e vemos um índio adulto entrar pela direita da tela, juntando-se às crianças no rio com um mergulho. Só então, diante da câmera, Kumaré Txicão toma a palavra e apresenta-se como o "videasta" do filme. Já em No tempo das chuvas (Pinhanta \& Pinhanta, 2000), essa apresentação é feita logo no começo. Após se apresentarem diante da câmera, os videastas retornam a seus postos fora de quadro e permanecem em silêncio no restante do filme.

\section{A Voz-Off}

Parece haver um receio em incorporar ao espaço fílmico o som que provém de fora de quadro. Estabelece-se uma espécie de regra: a equipe não pode chamar a atenção para a sua presença nos bastidores. Daí que suprimem as próprias vozes. Por trás dessa regra há a suspeita de que o vazamento de uma voz fora de quadro exigiria, já no plano seguinte, a imagem do dono da $v o z$-off.

Aqui talvez se faça necessário um parêntesis para distingui-la da voz-over. A voz-off é contígua e coetânea aos acontecimentos apresentados 
no campo, embora a sua fonte esteja fora (off) de nossa vista. Refere-se à voz de personagens situados fora de campo ou então às vozes dos integrantes da equipe de filmagem, desde que o fora de quadro esteja integrado ao espaço e tempo fílmico, como observamos, por exemplo, no filme Santiago. Já a voz-over é colocada no momento da montagem sobre (over) as imagens, ou seja, não é contígua e coetânea aos eventos apresentados no campo. Refere-se à voz que faz a narração de uma cena.

A mesma suspeita em relação à voz-off é compartilhada pela diretora Catarina Alves Costa, que também atua como cinegrafista em seus documentários: "o eu personagem eu prefiro dá-lo através da câmera e não através da minha voz porque aí é demasiado . . . Aí sou eu, Catarina. Então aí teria que aparecer eu fisicamente também" - transcrição do documentário homônimo Catarina Alves Costa (Marin \& Hikiji, 2007).

Como contraponto à concepção de que as palavras do cinegrafista devem ser ilustradas por seu corpo, temos a afirmação de Macdougall (2006) de que a visão da câmera já é suficiente para inscrever no filme o corpo do cinegrafista (o autor usa o termo "filmmaker", p. 54, que se traduz por cineasta, mas nesse trecho ele se refere especificamente aos filmes em que o cineasta atua também como cinegrafista). Apesar de se encontrar fora de quadro, o seu corpo e o dos personagens apresentados no campo possuem o mesmo estatuto. Podemos tirar daí duas conclusões. Ao contrário da suspeita de Catarina Alves Costa, não há necessidade alguma da aparição do cinegrafista diante da câmera caso sua voz vaze em campo. Mas, por outro lado, como a visão da câmera já basta como índice de corporeidade do cinegrafista, há quem encontrará nisso uma razão para dispensar a voz-off, tomando-a por supérflua. O próprio Macdougall adota em seus filmes um registro mais observacional, valendo-se minimamente de intervenções fora de quadro. Em The new boys (Macdougall, 2003), o autor acompanha o cotidiano de garotos que vivem na Doon School, um internato de elite indiano. Mantém-se discretamente com sua câmera em torno dos internos em todas as suas atividades. Mas à noite, no momento em que to- dos se deitam e a luz do dormitório se apaga, os garotos dizem: "Boa noite, Senhor!" Há um breve instante de indefinição, mas, convocado pelo campo, Macdougall responde e ouvimos a sua voz: "Boa noite!"

Apesar do receio em relação à voz-off, ela é um recurso que merece ser explorado. É claro que o registro da voz do cinegrafista imprime um ar amador à cena. De fato esse tipo de recurso é mais comum em vídeos caseiros (o exemplo do pai que incentiva o filho enquanto filma a partida de futebol na escola). Mas é possível obter efeitos bem interessantes com a voz-off. O diretor Alain Cavalier tem se valido bastante desse recurso, digamos, menos nobre do cinema. Em Chambre d'hôtel Nyon (Cavalier, 2010), entrevista concedida por ocasião do festival Visions du réel, as imagens foram captadas pelo próprio diretor e mostram o interior de um quarto de hotel, no qual se encontra também a entrevistadora. Entretanto a presença de ambos nos é dada apenas por suas vozes fora de quadro. Trata-se de uma configuração extremamente curiosa que frustra exatamente a expectativa pela inclusão de um plano com a imagem dos donos das vozes-off.

Já no filme Irène (Cavalier, 2009), o diretor, que também atuou como cinegrafista, procura objetos, lugares e pessoas que possam de algum modo the devolver a vida de sua esposa Irène, morta em 1972 num acidente de carro. Enquanto enquadra esses elementos com sua câmera, o diretor fora de quadro conta suas lembranças de Irène. Aqui a voz-off não descreve apenas a imagem apresentada no campo. Ela remete a algo ausente na tela: a imagem da pessoa atrás da câmera certamente, mas, mais do que isso, a imagem da falecida esposa.

Em $O$ prisioneiro da grade de ferro, há momentos em que a voz-off não serve apenas à imagem presente, mas, como em Irène, ela é utilizada a serviço da rememoração. Isso ocorre na seqüência "A noite de um detento" (inclusive a mais longa do filme com quase 15 minutos), em que os detentos Joel e Marcos retratam a experiência de adormecer na prisão e ver o sol nascer quadrado. Os dois se revezam no manuseio da câmera, mas não seguem o imperativo de não fa- 
lar enquanto operam a câmera. Ao enquadrar o metrô saindo da Estação Carandiru, Joel lembra, "faz tempo que não ando num desse", e imagina o dia em que pegará o metrô para voltar para casa. Joel filma uma torre da Paulista e lembra-se das vezes em que comemorou as glórias do Corinthians. Quando estouram fogos de artificio, Joel e Marcos lembram-se do réveillon, da casa, de suas famílias.

É claro que se trata de um momento relativamente isolado, pois em geral o filme estabelece uma convenção: para cada atividade e ocupação do presídio, vemos imagens que as exemplificam sobrepostas por uma locução que faz sua descrição. Ao invés da voz-off, aqui se configura uma voz-over. Não apenas ignoramos quem fala como não podemos determinar em que espaço e tempo esse alguém se encontra. Essa voz permanece indeterminada até o momento em que é situada por um plano com o detento falando diante da câmera. Embora ele se dirija a alguém fora de quadro, pouco importa se atrás da câmera está outro detento, o diretor de fotografia ou o diretor, pois a equipe nos bastidores se mantém o mais discretamente possível. A discrição é tanta que o detento poderia estar diante de uma câmera afixada em um tripé, sem qualquer cinegrafista, e isso pouca diferença faria. $\mathrm{Na}$ verdade, tudo o que importa jaz apenas no campo. Não faz diferença saber quem está fora de quadro operando a câmera, contanto que os elementos inseridos no campo sirvam à composição do autorretrato dos detentos.

O próprio diretor de fotografia, Aloysio Raulino, não seria capaz de precisar quem eram os cinegrafistas fora de quadro. Em debate ocorrido no Festival de Gramado,

o Aloysio falou num certo momento que ele não sabe mais quais são as imagens que ele captou e quais são as imagens que os presos captaram em alguns momentos. É claro que algumas são marcadas, como a noite do detento, mas quando tinham várias câmeras no local ele já não sabe diferenciar o que é dele e o que é dos outros. (citado por Contracampo, 2004, para. 15)

Quando o cinegrafista não fornece nenhum dado além da visão da câmera, não temos ou- tros indícios capazes de personalizar o fora de quadro. E o que torna "A noite de um detento" tão marcante é justamente o uso frequente da voz-off, que evidencia não apenas o espaço fora de quadro, mas também o cinegrafista enquanto personagem que vê e reage ao campo de maneira bastante particular.

\section{O Cinegrafista Fora de Quadro e os Eventos Situados no Campo}

A ideia de um cinegrafista fora de quadro em interação com o campo se desenvolve especialmente numa espécie de subgênero do terror e suspense chamado de found footage. Trata-se da apropriação de um termo originalmente cunhado na década de 1980, que veio a se juntar a outros como filme de colagem, "filmes de compilação" (Leyda, 1964), para designar filmes que trabalham com imagens preexistentes captadas por fontes alheias: por exemplo, o cineasta húngaro Péter Forgács, cuja obra recentemente passou em retrospectiva no Centro Cultural Banco do Brasil, trabalha com compilações de filmes antigos encontrados em acervos familiares.

O found footage do terror e suspense também trabalha com a ideia de organização de imagens alheias preexistentes, porém numa chave ficcional. São filmes que se fazem passar por documentários, dando a entender que o conteúdo das fitas apresentadas é da autoria de cinegrafistas mortos ou desaparecidos. Cannibal holocaust (Deodato, 1980) é provavelmente seu precursor. Segundo o anedotário do filme, após o seu lançamento, o diretor precisou dar provas de que os atores de fato estavam vivos para não ser acusado de homicídio. Das produções mais recentes podemos destacar A bruxa de Blair (Myrick \& Sánchez, 1999) e Cloverfield (Reeves, 2008).

Por se tratar de um falso documentário, o found footage apresenta uma particularidade relacionada ao fora de quadro, já que há uma distinção ente o cinegrafista de fato e o cinegrafista morto ou desaparecido na ficção. Essa divisão fica clara em Cloverfield. Em entrevista, o ator T. J. Miller, que interpreta o personagem-cinegrafista Hud, revelou que de fato gravou apenas 1/3 das imagens do filme (citado por Kirst, 2008, 
para. 11). Podemos falar então de dois tipos de fora de quadro: um válido no espaço e tempo da gravação, que nos remete aos cinegrafistas profissionais ou ao ator com a câmera na mão; e outro válido apenas no espaço e tempo fílmico, que nos remete ao personagem-cinegrafista Hud.

É preciso também lembrar que o found footage não se coloca como um registro em câmera subjetiva, técnica cujos limites já foram destacados por Sobchack (1991, pp. 236-248) na análise de Lady in the lake (Montgomery, 1947), filme composto quase integralmente por planos subjetivos. A autora demonstra o fracasso do filme em reproduzir a experiência corporal da visão através da câmera subjetiva. Para demonstrá-lo Sobchack serve-se de uma cena em particular em que o protagonista acende um cigarro enquanto esquadrinha as pessoas ao seu redor num salão. Nesse exato momento, o cigarro e as mãos do protagonista ocupam grande parte do plano. Se estivéssemos na mesma posição do protagonista, o mesmo cigarro, apesar de visível em nosso campo perceptivo, possuiria uma presença mais fraca do que a das pessoas, uma vez que nossa intenção estaria voltada para elas. A autora detém-se no fato de que nossa visão observa uma hierarquia de interesses, que conforma uma qualidade de presença para cada objeto em nosso campo perceptivo.

Em alguns momentos o filme até tenta construir essa hierarquia de interesses, mas segundo Sobchack (1991) através de meios incongruentes com a percepção humana. Numa cena em que o protagonista fala ao telefone, o filme borra o objeto que está fora de seu campo intencional, no caso o telefone, e destaca os outros objetos da sala que são foco de sua atenção. Mas, de acordo com a autora, não é que o objeto fica desfocado, como se estivéssemos com astigmatismo. Ele simplesmente tem uma presença latente.

A autora conclui pela não equivalência entre a experiência corporal da visão e a experiência visual proporcionada pela câmera subjetiva. Essa conclusão contraria de certo modo as iniciativas, observadas anteriormente nas pesquisas de Lahlou (2011) e Mausner (2005), de posicionar as câmeras na altura dos olhos dos participantes. Entretanto os dois autores estabelecem protoco- los para contornar essa não equivalência entre a visão humana e a visão da câmera. Como nem sempre o que se encontra no centro da imagem é o foco da atenção do participante, o pesquisador deve entrevistá-lo com o auxílio de trechos dos vídeos gravados para determinar qual era a hierarquia de interesses, ou seja, o que constituía o campo perceptivo do participante no momento de cada registro.

O mesmo problema suscitado por Lady in the lake não ocorre nos filmes de found footage, já que a câmera não finge ocupar o lugar dos olhos dos personagens, mas se coloca entre determinado elemento do campo e a resposta correspondente do cinegrafista fora de quadro. A mediação da câmera é, portanto, um elemento assumido pela própria narrativa. Por meio dela, temos o testemunho da reação do cinegrafista ao campo: seja a invasão de monstros alienígenas em Cloverfield, sejam os mistérios da floresta em A bruxa de Blair.

\section{A Interação Homem e Ambiente: O Participante Fora de Quadro diante do Campo}

Embora pareça inusitado, esse tipo de abordagem presente no found footage não interessa apenas aos domínios do cinema. Pesquisadores que investigam a interação entre homem e seu entorno podem pensá-la também em termos de fora de quadro e campo.

Retomemos os três trabalhos no âmbito da psicologia mencionados no início do artigo. $\mathrm{Na}$ pesquisa de Lahlou (2011), baseada em registros da rotina diária em ambientes domésticos, recreativos ou de trabalho, o espaço fora de quadro se insinua através da voz do participante gravada pelos microfones também instalados na armação de óculos. Mas, como são instruídos a agir de modo natural, o participante não fala consigo mesmo em voz alta, não comenta as atividades no momento mesmo em que as desempenha. Esses comentários serão colhidos num segundo momento, quando o pesquisador e participante assistem a trechos dos vídeos gravados. A revisão desse material é o momento em que o pesquisador tenta compreender a atividade mental 
dos participantes, investigando, por exemplo, o que pensavam enquanto praticavam determinada ação ou por que subitamente mudaram de direção na tentativa de cumprir certa tarefa.

Já na pesquisa com excursionistas conduzida por Mausner (2005), de um lado, no campo, vemos imagens da trilha, da paisagem e acompanhamos a progressão e o esforço dos participantes ao longo do percurso. De outro, a partir do som que provém do fora de quadro, ouvimos comentários e colóquios entre os excursionistas, que atuavam em duplas, ou mesmo solilóquios, quando não caminhavam lado a lado. A autora instruiu os participantes a falarem sempre, mesmo se estivessem sozinhos, sobre tudo o que lhes atraísse a atenção no decorrer da caminhada. A partir dos dados audiovisuais reunidos Mausner tenta compreender a dinâmica entre homem e natureza e estabelecer alguns critérios para o aprimoramento do traçado das trilhas.

Nessas duas pesquisas se evidencia mais a interação momentânea entre homem situado fora de quadro e ambiente apresentado no campo. Caso o interesse dos pesquisadores esteja no resgate da memória uma das opções é trabalhar a rememoração através do jogo entre a imagem presente no campo e a evocação de algo ausente por meio da voz-off, como vimos anteriormente no filme Irène e na sequência " $A$ noite de um detento" em $O$ prisioneiro da grade de ferro.

Foi o que ocorreu na pesquisa de Kohatsu (2005). O participante não apenas respondia ao espaço que tinha imediatamente diante de si, como também interagia com o espaço mediado pelas recordações: o "olhar não é prisioneiro do aqui e agora, ele não se acomoda somente à superfície do visível. Ele também é capaz de mergulhar na profundeza do tempo e recordar as experiências vividas naquele local" (p. 118).

Comparado ao método tradicional de filmagem, há uma vantagem clara em confiar a filmagem ao participante, posicionando-o fora de quadro, atrás das lentes, pois na configuração mais comum, na qual o participante é apresentado diante da câmera, precisamos lidar com dois níveis de leitura, visto que há duas relações em jogo: uma que se desenvolve no campo entre os participantes e outra estabelecida entre eles e o pesquisador fora de quadro. Em geral, as pesquisas tratam mais do primeiro nível de leitura. Já o segundo começou a ser abordado a partir da década de 1980, quando a posição do pesquisador se tornou definitivamente uma questão. $\mathrm{O}$ reconhecimento da participação dos próprios pesquisadores na constituição do campo levou-os à adoção de uma análise mais reflexiva. Lomax e Casey (1998), por exemplo, analisam os momentos em que a presença da câmera e do próprio pesquisador fora de quadro se imiscui na relação dada no campo entre as participantes (no caso, a interação entre mãe e parteira durante consultas pós-natal). Mas uma nova questão foi introduzida pela reflexividade, tal como foi designado esse modo circular de pensar, ocupado com a participação dos próprios autores no fenômeno pesquisado. Para Holliday (2000), a análise reflexiva fez com que os pesquisadores perdessem de vista os participantes, focados que estavam em analisar o quanto interferiam fora de quadro.

Agora se é o participante quem opera a câmera, o campo e o fora de quadro não valem isoladamente. Não há uma divisão de escopo: examinar o que se passa no campo ou o que se passa fora de quadro. $\mathrm{O}$ foco não está num ou noutro, mas no modo como um se relaciona com outro. Está em consideração justamente a relação que o participante fora de quadro mantém com os elementos apresentados no campo.

\section{Registro Direto ou Indireto?}

Embora reduza as camadas de leitura, a opção de confiar a filmagem ao participante também coloca uma questão. Não podemos dizer que a relação entre o participante fora de quadro e o que aparece em campo nos registros obtidos seja propriamente direta, sem qualquer tipo de mediação do pesquisador. Há outro tipo de fora de quadro, outro elemento invisível que participa na configuração do campo. O filme Irène novamente pode ser útil em nossa argumentação. Sempre que começa uma tomada, Cavalier já está diante dos objetos que se associam à Irène. Ele não chega casualmente com sua câmera até eles. Há algo antes do quadro, uma preparação anterior 
a cada tomada. Essa anterioridade também pode ser pensada no caso de um vídeo registrado pelo participante, pois, antes mesmo de começarem as gravações, há todos os preparativos conduzidos pelo pesquisador, por exemplo, os primeiros contatos com os participantes, as entrevistas, as instruções para a coleta de dados, para delimitar, por exemplo, o que pode ser filmado e como a filmagem deve ser feita. A gravação surge em resposta ao contexto específico de um projeto de pesquisa. Antes de qualquer objeto ser colocado no campo cinematográfico pelo participante, há o campo de investigação estabelecido pelo pesquisador. Depois de montado o set de pesquisa, não há nada que apague as pegadas do pesquisador, nem mesmo o fato de ele confiar o registro dos vídeos aos próprios participantes.

Essa questão já havia sido colocada por Gibson (2005): "o pesquisador, fisicamente presente ou não, é inevitavelmente parte do universo de pesquisa em estudo" (p. 36, tradução nossa). A autora trabalhou o tema da identidade com portadores de distrofia muscular de Duchenne a partir de vídeos que registravam situações cotidianas vividas por eles (video diaries). Em função da limitação motora, os participantes gravavam com câmeras adaptadas em seus bonés ou então recorriam à ajuda de outras pessoas: em alguns casos a própria pesquisadora atuava como cinegrafista; em outros, quando ela não estava presente, familiares ou amigos operavam a câmera. Diferente de autores que minimizam o papel do pesquisador quando o material é gravado pelo próprio participante (Rich, Lamola, Gordan, \& Chalfen, 2000, citado por Gibson, 2005, p. 36), a autora não trata os videodiários como produções diretas, livres da interferência do pesquisador, mesmo nos casos em que foram gravados em sua ausência.

Gibson (2005) aponta para a necessidade de considerarmos com cautela a ideia de que um vídeo feito pelo participante ofereça um registro direto. Mas há quem não se dará por contente com isso. Podemos imaginar o passo seguinte daqueles que acharam que confiar a gravação ao participante seria a solução quando a questão girava em torno do fato de o pesquisador operar a câmera. A partir do momento em que se questiona o caráter direto de um registro feito pelo participante, essas mesmas pessoas apostarão todas as suas fichas na busca de material preexistente que não dependeu de um contexto de pesquisa para ser produzido. Seguindo essa tendência, já é bem possível imaginar autores realmente interessados em fontes independentes recorrendo ao acervo disponível em sites como o YouTube ou mesmo o Opentopia (site com transmissão ao vivo de imagens de webcams e câmeras de vigilância). Mas isso diria respeito apenas às filmagens. Vemos que o assunto ainda não se daria por encerrado, restando, por exemplo, a discussão sobre a montagem do material.

Essa busca por um registro direto, independente atende a uma espécie de ideal de objetividade em que é preciso mitigar a influência do pesquisador para fazer valer a visão do participante. Há nisso um paralelo com a suposição de Ganda e dos diretores de $5 x$ favela de que era preciso "matar" quem os precedeu (Rouch e Meirelles, respectivamente), isto é, fazer os próprios filmes, para que suas visões finalmente pudessem ser representadas.

Entretanto não precisamos seguir a controvérsia sobre autorrepresentação. O uso de registros obtidos por fontes independentes não se vincula necessariamente com a busca de representação direta, sem mediação.

No âmbito do cinema, isso ocorre especialmente nos filmes de found footage, agora no sentido de "filme de compilação". No Brasil, o documentário Pacific (Pedroso, 2009) é um exemplo recente de filme que trabalha com imagens preexistentes captadas por fontes alheias. Ao final de um cruzeiro no navio Pacific a equipe de produção abordou passageiros que haviam filmado a viagem. O documentário foi então construído a partir de vídeos que os passageiros guardariam para si mesmos, para serem vistos no máximo por familiares e amigos. Ao se reapropriar desses materiais a intenção do filme não é buscar uma representação direta do olhar dos passageiros, sem a mediação dos realizadores, até porque nesse caso, como os passageiros não participaram da edição do material, transferiria o problema da gravação para o da montagem. Ao 
invés disso, há em Pacific a tentativa de dar sobrevida a imagens fugazes, que "feitas e armazenadas às pressas, seriam provavelmente fadadas ao esquecimento" (Silva, 2012, p. 9).

No âmbito acadêmico, também encontramos trabalhos que se reapropriam de imagens preexistentes captadas por fontes alheias. É o caso de pesquisadores que analisam vídeos caseiros antigos de famílias com crianças posteriormente diagnosticadas como autistas, em busca de sinais precoces do distúrbio (para uma revisão de literatura sobre o assunto, cf. Saint-Georges et al., 2010). Trata-se de um uso bastante específico e diverso, que não tem qualquer relação com a busca por registros livres da mediação do pesquisador. Apenas utilizam o material a fim de formular possíveis bases para um diagnóstico precoce do autismo.

\section{Campo e Fora de Quadro: Visível e Invisível}

A opção de confiar a filmagem ao participante também não representa a necessidade de "matar" o pesquisador. Não é motivada pela busca de uma representação direta, na qual a influência do pesquisador é diminuída. O que leva então um pesquisador a optar por confiar a filmagem ao participante? Isso talvez fique claro ao compararmos duas pesquisas que abordam a visitação de museus. A primeira coloca o participante fora de quadro e a segunda, no campo:

Lachapelle (1999) emprestou câmeras a alguns visitantes de museus para que registrassem o processo de leitura de obras de arte. Nos vídeos produzidos, o fora de quadro é ocupado pelo visitante que fornece suas interpretações por meio da voz-off e o campo é composto basicamente por planos gerais e closes das obras. Já Lehn e Heath (2006) optaram por colocar as obras e os visitantes no campo e não trabalharam com elementos fora de quadro. Antes das gravações foram feitos estudos dos espaços expositivos a fim de determinar a melhor posição das câmeras e microfones. Os equipamentos foram dispostos no museu de modo a garantir o registro do comportamento dos visitantes sem necessidade de cinegrafistas. Enquanto Lachapelle aborda o processo individual de recepção de obras de arte, Lehn e Heath tratam do processo coletivo, que inclui tanto a interação com o ambiente, o mobiliário e os dispositivos expositivos, como a interação social que ocorre quando os visitantes estão diante das obras de arte, seja com seus acompanhantes, seja com pessoas desconhecidas.

A opção feita por Lachapelle (1999) de colocar o participante fora de quadro e a opção feita por Lehn e Heath (2006) de colocá-lo no campo não se baseou no caráter direto ou indireto do registro, mas no recorte pretendido em suas pesquisas. A que se ativeram os autores? No segundo caso, aos comportamentos observáveis: a interação com o mobiliário, a socialização entre visitantes. No primeiro, aos processos internos, imateriais: a interpretação, o juízo estético. Vale lembrar que esse mesmo domínio impalpável foi perseguido pelas pesquisas psicológicas de Mausner, Kohatsu e Lahlou: a percepção da paisagem e de trilhas, a vivência e a memória do bairro, processos mentais durante atividades cotidianas. Talvez possamos verificar aí uma tendência: Para quem deseja sondar aspectos visíveis do ser, eis o campo. Agora, se o desejo for sondar o invisível, a resposta estará bem fora de quadro.

\section{Referências}

Aumont, J., Bergala, A., Marie, M., \& Vernet, M. (1995). A estética do filme. Campinas, SP: Papirus.

Bernardet, J.-C. (2004). Vídeo nas aldeias, o documentário e a alteridade. Catálogo da mostra vídeo nas aldeias: Um olhar indígena (pp. 8-11). Rio de Janeiro, RJ: Centro Cultural Banco do Brasil.

Carneiro, M., Novais, W., Felha, R., Amaral, C., Vidigal, L., Barcellos, C., \& Bezerra, L. (Diretores). (2010). $5 x$ favela, agora por nós mesmos [DVD]. Culver City, CA: Sony Pictures.

Cavalier, A. (Diretor). (2009). Irène [DVD]. Lisboa, Portugal: Clap Filmes.

Cavalier, A. (Director). (2010) Chambre d'hôtel Nyon. Visions du Réel. Retrieved October 10, 2012, from http://youtu.be/qRQT1FPa5CQ 
Contracampo. (2004). Entrevista com Paulo Sacramento e Aloysio Raulino. Contracampo: Revista de Cinema, 59. Recuperado em 10 de outubro, 2012, de www.contracampo.com.br/59/entrevistapaulosacramento.htm

Corrêa, M. (2004). Vídeo das aldeias. In Catálogo da mostra vídeo nas aldeias: Um olhar indígena (pp. 33-39). Rio de Janeiro, RJ: Centro Cultural Banco do Brasil.

De, J. (Director). (2010). Bróder [DVD]. Culver City, CA: Sony Pictures.

Deodato, R. (Director). (1980). Cannibal Holocaust [DVD]. Los Angeles, CA: Grindhouse Releasing.

Elias, R. (Diretor). (2003). De passagem [DVD]. Rio de Janeiro, RJ: Video Filmes.

Farias, M., Borges, M., Diegues, C., Andrade, J. P. de, \& Hirszman, L. (Diretores). (1962). Cinco vezes favela [DVD]. Rio de Janeiro, RJ: Centro Popular de Cultura, União Nacional dos Estudantes.

Flaherty, R. (Director). (1922). Nanook, o esquimó [DVD]. Toronto, Canadá: Silver Screen Classics.

Gibson, B. E. (2005). Co-producing video diaries: The presence of the 'absent' researcher. International Journal of Qualitative Methods, 4(4), 34-43.

Gonçalves, M. A. (2008). O real imaginado - Etnografia, cinema e surrealismo em Jean Rouch. Rio de Janeiro, RJ: Topbooks.

Guidi, M. A. A. (1972). Desenvolvimento de uma técnica instrumental de registro cinematográfico de comportamentos de atta sexdens rubropilosa (Tese de doutorado, Instituto de Psicologia, Universidade de São Paulo, SP, Brasil).

Henley, P. (2009). The adventure of the real. Jean Rouch and the craft of ethnographic cinema. Chicago, IL: University of Chicago Press.

Holliday, R. (2000). We've been framed: Visualising methodology. Sociological Review, 48(4), 503521.

Kirst, B. (2008). TJ Miller. Horror Society. Retrieved October 10, 2012, from www.horrorsociety. com/2008/12/15/interview-tj-miller

Kohatsu, L. N. (2005). Do lado de fora da escola especial: Histórias vividas no bairro e contadas por ex-alunos por meio do vídeo (Tese de doutorado, Instituto de Psicologia, Universidade de São Paulo, SP, Brasil).
Kunuk, Z. (Director). (2001). Atanarjuat, o corredor [DVD]. Montreal, Canadá: Igloolik Isuma Productions.

Lachapelle, R. (1999). Informant-made videos: A research and educational tool. Studies in Art Education, 40(3), 242-257.

Lahlou, S. (2011). How can we capture the subject's perspective? An evidence-based approach for the social scientist. Social Science Information, 50(3-4), 607-655.

Lehn, D. vom, \& Heath, C. (2006). Discovering exhibits: Video-based studies of interaction in museums and science centres. In H. Knoblauch, J. Raab, H.-G. Soeffner, \& B. Schnettler (Orgs.), Video-analysis: Methodology and methods. Qualitative audiovisual data analysis in Sociology (pp. 101-113). Berna, Switzerland: Peter Lang.

Lewin, K. (Director). (1925). Field Forces as Impediments to a Performance. TheVirtualLaboratory. Retrieved October 10, 2012, from http://youtu. be/BeS9R4wLcgY

Leyda, J. (1964). Films beget films: A study of the compilation film. London: George Allen \& Unwin.

Lomax, H., \& Casey, N. (1998). Recording social life: Reflexivity and video methodology. Sociological Research Online, 3(2). Retrieved October 10, 2012, from http://icar.univ-lyon2.fr/ ecole_thematique/idocora/documents/Lomax_ Casey_\%20Recording_Social_Life.pdf

Lund, K., \& Lins, P. (Diretores). (2002). Cidade dos homens: Correio [DVD]. Rio de Janeiro, RJ: Som Livre.

Lund, K., \& Tripa, E. (Diretores). (2003). Cidade dos homens: Os ordinários [DVD]. Rio de Janeiro, RJ: Som Livre.

Macdougall, D. (Director) (2003). The new boys [DVD]. Berkeley, CA: Berkeley Media LLC.

Macdougall, D. (2006). The corporeal image. Princeton, IL: Princeton University Press.

Marin, N., \& Hikiji, R. S. (Diretoras). (2007). Catarina Alves Costa [DVD]. São Paulo, SP: Laboratório de Imagem e Som em Antropologia, Universidade de São Paulo.

Marker, C., \& Marret, M. (Diretores). (1968). Até breve, eu espero [DVD]. Paris: Éditions Montparnasse.

Martins, J. R. (2011a). Encantaria na umbanda (Dissertação de mestrado, Faculdade de Filosofia, 
Ciências e Letras de Ribeirão Preto, Universidade de São Paulo, Ribeirão Preto, SP, Brasil).

Martins, J. R. (Diretora). (2011b). Encantaria na umbanda. Recife, PE: III Festival do Filme Etnográfico do Recife.

Mausner, C. (2005). Capturing the hike experience on video: A new methodology for studying human transactions with nature. Proceedings of the 2005 Northeastern Recreational Research Symposium, 168-176.

Meirelles, F., \& Lund, K. (Diretores). (2000). Palace II [DVD]. São Paulo, SP: O2 Filmes.

Meirelles, F. (Diretor), \& Lund, K. (Codiretora). (2002). Cidade de Deus [DVD]. São Paulo, SP: Imagem Filmes.

Merten, L. C. (2010). Sim, o morro (agora) tem vez. Estadão.com.br. Recuperado em 10 de outubro, 2012, de www.estadao.com.br/estadaodehoje/20100827/not_imp601003,0.php

Miranda, L. L. (2007). Consumo e produção de subjetividade nas TVs comunitárias. Revista do Departamento de Psicologia, 19(1), 199-213.

Montgomery, R. (Director). (1947). Lady in the lake [DVD]. Burbank, CA: Warner Bros.

Myrick, D., \& Sánchez, E. (Diretores). (1999). A bruxa de Blair [DVD]. Alphaville, SP: Europa Filmes.

Neiva-Silva, L., \& Koller, S. H. (2002). O uso da fotografia na pesquisa em Psicologia. Estudos de Psicologia (Natal), 7(2), 237-50.

Nichols, B. (2007). Introdução ao documentário. Campinas, SP: Papirus.

Ozu, Y. (Diretor). (1960). Dia de outono [DVD]. São Paulo, SP: Cinemax

Pedroso, M. (Diretor). (2009). Pacific [DVD]. São Paulo, SP: Vitrine Filmes.

Piault, M.-H. (1997). Uma antropologia-diálogo: A propósito do filme de Jean Rouch Moi, un Noir. Cadernos de Antropologia e Imagem, 4.

Pinhanta, I., \& Pinhanta, V. (Diretores). (2000). No tempo das chuvas [DVD]. Olinda, PE: Vídeo nas Aldeias.

Portal Vermelho. (2010). Cineastas da favela criticam Cidade de Deus e Tropa. Portal Vermelho. Recuperado em 10 de outubro, 2012, de http://www. vermelho.org.br/noticia.php?id_secao $=11 \&$ id_ noticia $=133656$
Reeves, M. (Director). (2008). Cloverfield [DVD]. Los Angeles, CA: Paramount.

Rouch, J. (Diretor). (1958). Eu, um negro [DVD]. Rio de Janeiro, RJ: Video Filmes.

Rouch, J., \& Morin, E. (Diretores). (1961). Crônica de um verão [DVD]. Rio de Janeiro, RJ: Video Filmes.

Sacramento, P. (Diretor). (2003). O prisioneiro da grade de ferro [DVD]. São Paulo, SP: Califórnia Filmes.

Saint-Georges, C., Cassel, R. S., Cohen, D., Chetouani, M., Laznik, M.-C., Maestro, S., \& Muratori, F. (2010). What studies of family home videos can teach us about autistic infants: a literature review. Research in Autism Spectrum Disorders, 4, 355-366.

Salles, J. M. (Diretor). (2007). Santiago [DVD]. Rio de Janeiro, RJ: Video Filmes.

Silva, S. T. L. (2012). Subjetividade, arquivos familiares e found footage no documentário brasileiro contemporâneo. In Anais do III Congresso Internacional de la Associación Argentina de Estudios de Cine y Audiovisual. Recuperado em 10 de outubro, 2012, de http://www.asaeca.org/ aactas/tenorio_luna_da_silva_sabrina_-_ponencia.pdf

Sobchack, V. (1991). The adress of the eye. A phenomenology of film experience. Princeton, IL: Princeton University Press.

Txicão, K. [Karané], Txicão, K. [Kumaré], \& Txicão, N. (Diretores). (2001). Das crianças Ikpeng para o mundo [DVD]. Olinda, PE: Vídeo nas Aldeias.

Worth, S., \& Adair, J. (1970). Navajo filmmakers. American Anthropologist, 72(1), 9-34. 